\title{
Uma breve introdução à pesquisa sobre paz transracional e transformação elicitiva de conflito
}

\begin{abstract}
A brief introduction to transrational peace research and elicitive conflict transformation
\end{abstract}

Una breve introducción a la investigación de paz transracional y transformación elicitiva de conflictos

\section{Wolfgang Dietrich}

- É Ph.D. em história e literatura pela Universidade de Innsbruck em 1980 e doutor em Direito na mesma universidade. A partir de 1990 assumiu o cargo de Professor Adjunto em Ciência Política da Universidade de Innsbruck.

- Atualmente é diretor da Unidade para a Paz e Estudos de Conflitos da Escola de Ciências Sociais e Políticas da Universidade de Innsbruck, Áustria. É diretor do Programa de Mestrado em Paz, Desenvolvimento, Segurança e Transformação de Conflitos Internacionais na mesma universidade. Também é responsável pela Cátedra UNESCO para Estudos de Paz e membro da Comissão Austríaca da UNESCO.

- Wolfgang Dietrich passou a maior parte dos anos oitenta na América Central. Foi presidente da seção austríaca de anistia internacional de 1989 a 1991. Nos anos 90 realizou pesquisas na América Latina, Caribe, Índia, África Oriental e no Sudeste Asiático. Desde os anos noventa, seu foco é a transformação de conflitos e pesquisa sobre a paz.

- Conta com mais de 200 textos acadêmicos foram publicados em inglês, alemão, espanhol, francês, russo, português e farsi.

- E-mail: wolfgang.dietrich@uibk.ac.at 


\section{Resumo}

Este artigo é uma síntese da trilogia Muitas pazes do autor. Este trabalho aprofunda a filosofia das muitas pazes e de paz transracional e deriva da famosa pirâmide de conflito de Lederach, com um entendimento sistêmico mais amplo do conflito como um fenômeno relacional. Além disso, oferece ferramenta para a análise desses processos complexos que ocorrem nas "fronteiras de contato em movimento" humanas. Por fim, introduz ressonância, correspondência e homeostase como princípios de mapeamento elicitivo de conflito.

\section{PALAVRAS-CHAVE: FILOSOFIA DE PAZ • TRANSFORMAÇÃO DE CONFLITOS • MAPEAMENTO DE CONFLITOS.}

\section{Abstract}

This article is a summary of the author's trilogy, Muitas pazes. This work deepens the philosophy of many peaces and of transrational peace and derives from the famous Lederach conflict pyramid, with a broader systemic understanding of conflict as a relational phenomenon. In addition, it offers a tool to analyze these complex processes that occur in the human "contact boundaries in movement." Finally, it introduces resonance, correspondence and homeostasis as principles of elicitable mapping of conflicts.

KEYWORDS: PEACE PHILOSOPHY • CONFLICT TRANSFORMATION • CONFLICT MAPPING.

\section{Resumen}

Este artículo es una síntesis de la trilogía Muitas pazes del autor. Este trabajo profundiza la filosofía de las muchas paces y de paz transracional y deriva de la famosa pirámide de conflicto de Lederach, con un entendimiento sistémico más amplio del conflicto como un fenómeno relacional. Además, ofrece herramienta para el análisis de estos procesos complejos que ocurren en las "fronteras de contacto en movimiento" humanas. Por último, introduce resonancia, correspondencia y homeostasis como principios de mapeo elícito de conflicto. 
ANO 15 • NÚMERO 28 • 1ํㅗ․ 2018 • ORGANICOM

\section{UMA BREVE INTRODUÇÃO À PESQUISA SOBRE PAZ TRANSRACIONAL}

\section{O QUE É FILOSOFIA DE PAZ TRANSRACIONAL?}

$\mathrm{P}$ az transracional é um termo relativamente novo, criado na Cátedra de Estudos de Paz da Organização das Nações Unidas para a Educação, a Ciência e a Cultura (Unesco), na Universidade de Innsbruck, no início deste milênio. É resultado de nossa pesquisa sobre as diferentes percepções e interpretações da paz na história e na cultura. Encontramos quatro grupos dominantes de interpretações, que denominamos famílias de pazes: energética, moral, moderna e pós-moderna. Cada uma circula em torno de um valor chave específico: a paz energética tem tudo a ver com harmonia; a interpretação moral enfatiza a justiça; o entendimento moderno de paz solicita segurança; e a abordagem pós-moderna lida com a questão da(s) verdade(s).

Uma vez que nenhum desses valores surge isolado na vida social, tentamos combiná-los de maneira holística e identificamos 0 equilíbrio dinâmico dos quatro aspectos como um conceito de paz mais amplo, que então chamamos trans-racional, porque leva em consideração e aplica a racionalidade da ciência moderna, embora transgrida seus limites e abranja holisticamente todos os aspectos da natureza humana para a interpretação de paz. Ela é racional e muito mais; é, por exemplo, emocional, mental e espiritual (Dietrich, 2008). A pesquisa sobre paz transracional como um empreendimento acadêmico se dedica ao encontro, às relações, aos estilos de comunicação e aos comportamentos dos seres humanos, entendidos como as chamadas "fronteiras de contato em movimento" da terapia Gestalt (Quitmann, 1996). Se e quando esses encontros nas fronteiras de contato são perturbados, então os episódios caracterizam-se como "conflitos", de acordo com a linguagem comum. Estamos em busca de métodos adequados para lidar com tais conflitos no interior da moldura conceitual lógica da epistemologia transracional.

Tomamos emprestado o termo "transracional" de Ken Wilber (1995), cuja visão filosófica é uma das nossas muitas inspirações, mas não uma diretriz. A escola de Innsbruck não se configura como um ramo da abordagem integrativa de Wilber. Não compartilhamos da epistemologia evolucionista. Entretanto, segundo a Figura 1, adotamos sua famosa matriz do interno e externo, respectivamente aspectos individuais e coletivos da orientação humana, como fundamento para nosso modelo da inter-relação das famílias de paz e suas combinações para o equilíbrio dinâmico que denominamos pazes transracionais:

Figura 1: A matriz das pazes transracionais

\begin{tabular}{|c|c|c|}
\hline $\begin{array}{l}\text { Interior } \\
\text { Energética e pós-moderna }\end{array}$ & $\begin{array}{l}\text { Exterior } \\
\text { Moral e moderna }\end{array}$ & \\
\hline $\begin{array}{l}\text { Intencional } \\
\text { Paz que deriva da Harmonia }\end{array}$ & $\begin{array}{l}\text { Comportamental } \\
\text { Paz que deriva da Segurança }\end{array}$ & $\begin{array}{l}\text { Singular } \\
\text { (individual) }\end{array}$ \\
\hline $\begin{array}{l}\text { Cultural } \\
\text { Paz que deriva da Verdade }\end{array}$ & $\begin{array}{l}\text { Social } \\
\text { Paz que deriva da Justiça }\end{array}$ & $\begin{array}{l}\text { Plural } \\
\text { (coletiva) }\end{array}$ \\
\hline
\end{tabular}

Fonte: Dietrich, 2008, p. 385.

Enquanto a matriz é uma tentativa de apresentar de maneira resumida um trabalho de pesquisa elaborado em mais de uma década, o empreendimento acadêmico será relevante apenas se puder ser aplicado na prática do trabalho de paz e conflito. Com esse objetivo, relacionamos nossas descobertas à obra orientada à práxis de John Paul Lederach (1997), que, no início de sua carreira, derivou um padrão semelhante ao nosso a partir do Salmo 85:10, na Bíblia: "O amor e a fidelidade se encontrarão; a justiça e a paz se beijarão". Baseando-se no salmo, Lederach traçou sua matriz dos quatro valores básicos: verdade, misericórdia, justiça e paz, e a denominou "um lugar de reconciliação" (Lederach, 1997, p. 28, tradução nossa).

Ainda mais importante para a pesquisa sobre paz foi sua pirâmide de conflito, muitas vezes copiada e diversificada. Na versão original, essa pirâmide (Lederach, 1997, p. 39) indica que todos os atores de um sistema disfuncional ou conflituoso interagem por todos os vários estratos sociais, desde a base popular até o segmento médio dos dirigentes regionais e líderes aos chefes de Estado, e que todos são relevantes para o processo de transformação na sequência de situações de violência. Portanto, 
de acordo com Lederach, os atores precisam ser abordados de maneira contextual, empregando-se formas adequadas de intervenção. 0 seu mérito mais importante, consequentemente, foi deslocar a atenção do individual ou do grupo para a relação, como sendo o fator chave do trabalho de conflito. Ao fazê-lo, seu modelo tornou-se um impulsionador pioneiro da transição do pensamento mecanicista para o sistêmico nos estudos de paz e conflito, o que foi crucial para o desenvolvimento da pesquisa sobre paz transracional. A Figura 2 mostra a versão original da pirâmide de Lederach:

Figura 2: Pirâmide de Lederach, versão original

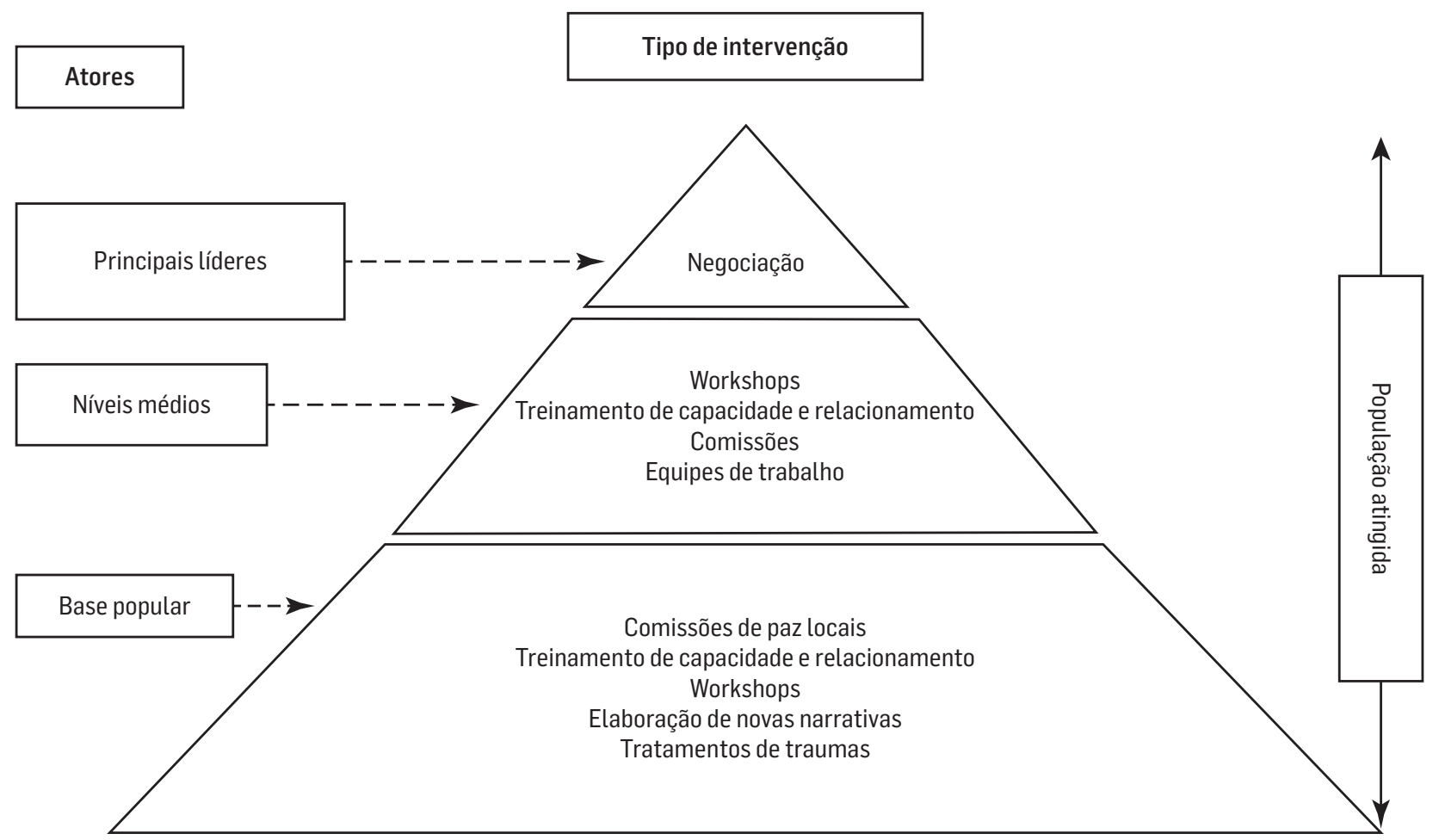

Fonte: Lederach, 1997, p. 39.

A pirâmide de Lederach foi inicialmente apresentada nessa visão estritamente lateral vertical. Os quatro valores bíblicos foram incluídos apenas de modo implícito no diagrama que, consequentemente, era bidimensional. Entretanto, Lederach $(1997,2003)$ expandiu o famoso triângulo de Johan Galtung (1990), que representa a violência física, estrutural e cultural, para uma quarta dimensão. Lederach dividiu o aspecto físico de Galtung nos aspectos pessoal e relacional. Ele, portanto, reconheceu a conexão entre os processos internos de uma pessoa e as relações sociais, que, por sua vez, consistem em situações imediatas, um contexto mais amplo e uma camada mais profunda de percepção, interpretação e ação. A inevitável e constantemente renovada necessidade por escolhas responsáveis, assumidas por pessoas livres, por conseguinte tornou-se o fundamento sistêmico do trabalho de conflito de Lederach. Isso nos inspirou a expandir a pirâmide de forma a representar os quatro quadrantes, "pessoa", "estrutura", "relação" e "cultura", em lugar de uma estrutura bidimensional. Vista de cima, segundo a Figura 3, a pirâmide seria assim:

Figura 3: A pirâmide de Lederach ampliada para o modelo transracional tridimensional; vista de cima

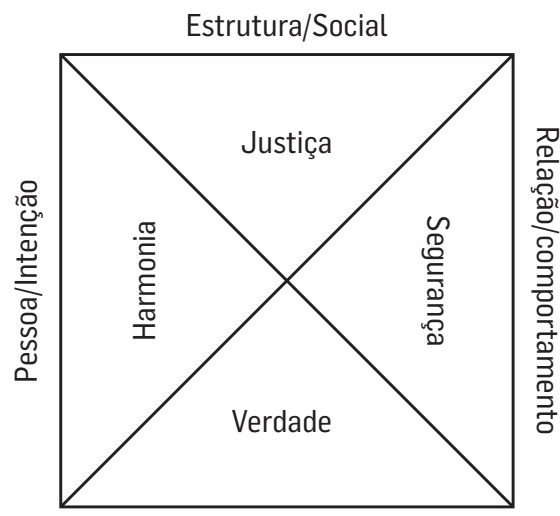

Cultura/Coletivo 
A partir daí é possível considerar-se a existência humana como uma fronteira de contato em movimento, beneficiando-se das realizações da psicologia humanista, enquanto se inicia a espiral do episódio para o epicentro de um conflito, de acordo com Lederach (2003). 0 episódio é aquilo que percebemos como a situação imediata e visível na superfície de um conflito. 0 epicentro, que consiste na força motriz da vida, só pode ser encontrado além das camadas mais profundas do Ego das pessoas envolvidas. É preciso um olhar bem treinado e muita empatia para enxergar além dos problemas apresentados e assim desvendar os padrões mais profundos de relacionamento, incluindo o contexto em que o conflito se expressa. A consequência disso é que as questões intrapessoais relativas ao desejo sexual, pertencimento social, laços emocionais e consciência mental se tornaram temas na pesquisa de paz e trabalho de conflito tanto quanto as esferas interpessoais da família, comunidade, sociedade e policidade global. A correspondência das dimensões interior e exterior é aprofundada para cada aspecto. 0 significado transracional da pirâmide, ou seja, do conflito, não pode ser entendido com base em um episódio na sua superfície. A pessoa, da forma como é apresentada por Lederach, corresponde ao individual e ao interior que, em transracionalidade, representa o quadrante energético da paz derivada da harmonia.

Os indivíduos em sua maioria percebem a paz como um fluxo harmonioso de todas as coisas existentes, desde que não sejam questionados a respeito de valores e normas religiosas, culturais, sociais ou políticas. Por essa razão, no diagrama, o quadrante da paz pela harmonia é referido como a porta de entrada para as camadas por trás da persona. Vemos, assim, a correspondência entre os processos internos de dada pessoa e as relações sociais - relações que, por sua vez, consistem em situações imediatas, um contexto mais amplo e uma camada mais profunda de percepção, interpretação e ação. 0 desejo de paz mediante harmonia conduz da camada mais externa à próxima camada mais profunda. As camadas interiores afetam as exteriores como promotoras ou perturbadoras da harmonia e vice-versa. Dessa forma, a pirâmide deve ser vista como uma boneca matrioska ou uma caixa chinesa. Em seu interior, há pirâmides menores do Ego e do Self como um epicentro de múltiplas camadas. Franz Ruppert (2002) sugere as seguintes camadas terapêuticas entre o episódio social e o epicentro energético: sociedade, parentesco, núcleo familiar, sujeito, corpo, órgãos, células e átomos. Em sua variante mais radical, essa reflexão envolve todas as camadas concebíveis, desde a atômica até a cósmica. Entretanto, no que concerne à pesquisa sobre paz e conflito, como uma ciência social, é desafiador o bastante considerar as camadas que inequivocamente perpassam a máscara da pessoa e que inequivocamente contribuem de maneira evidente para 0 episódio do conflito na superfície.

Para nomear as camadas que subjazem a superfície material e pessoal, refiro-me à ideia do chacra da Tantra Yoga, na tradição Patanjali e Shankara (Bharati, 2001). De acordo com essa filosofia, há uma camada sexual, uma socioemocional e uma mental que subjazem a superfície material e pessoal, o episódio da fronteira de contato do Ego em movimento. Além (no interior) da camada mental, existe a camada espiritual, que já não se refere mais ao Ego, mas ao que a filosofia do Yoga chama de Self, o aspecto que permanece depois do desmantelamento de todas as camadas do Ego. Por se tratar de um potencial e de uma propriedade naturalmente humana, a camada espiritual é acessível a todas as pessoas; porém, é difícil usar palavras para falar dela de maneira significativa, precisamente por ser transracional, por estar além da razão. A mente não possui palavras para expressá-la, embora experiências de clímax - e de paz - ocorram precisamente lá, onde o Ego é retorcido, isto é, quando, por um instante, a unidade primordial, harmoniosa e eterna do indivíduo e da existência universal é vivenciada pelo ser humano. Portanto, a pesquisa sobre paz precisa levar em conta a alta relevância para todos os temas, relações e ações desse aspecto humano que, no entanto, não pode ser abordado nem definido de modo apenas racional. É preciso adotar métodos e entendimentos transracionais. Inaugura-se, assim, um intrigante capítulo para a pesquisa sobre paz. Tentei articular esse modelo das camadas adicionando uma seção lateral à pirâmide de Lederach. Com isso, não identifico categorias empíricas, mas sugiro um padrão visual de análise e descrição conforme a Figura 4: 
Figura 4: As camadas intrapessoais da pirâmide de Lederach; vista lateral

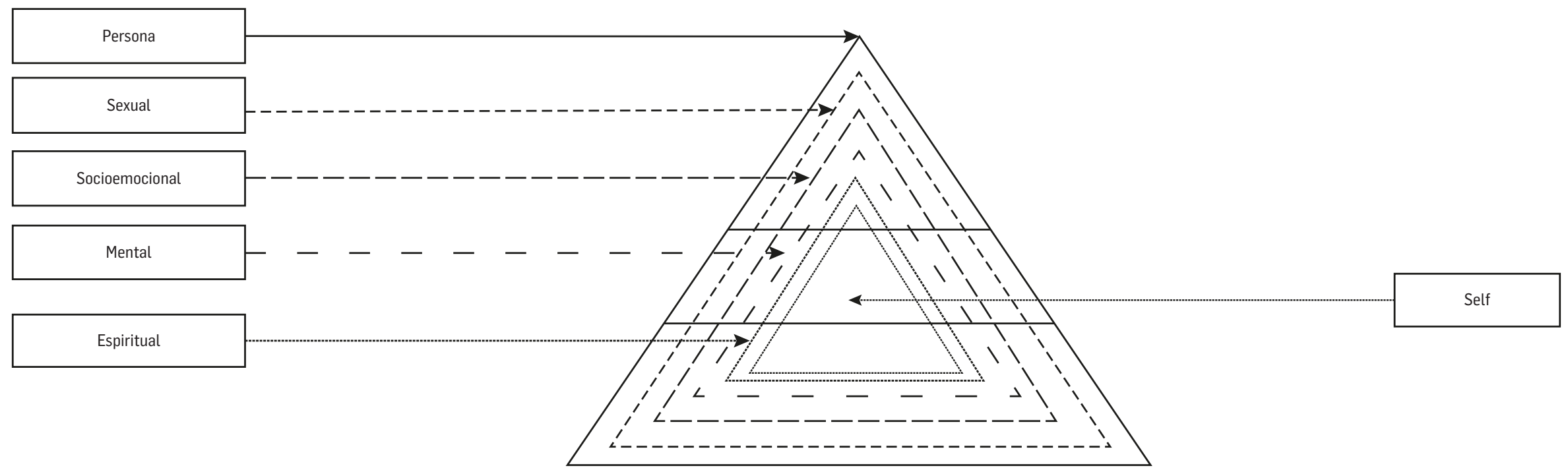

Fonte: Dietrich, 2011, p. 355.

Continuando com o princípio da boneca matrioska, as camadas internas da pirâmide possuem os campos horizontais e as dimensões verticais da superfície material-pessoal. As camadas matrioskas estão conectadas e interagem umas com as outras, ou seja, não estão empilhadas simplesmente umas sobre as outras permanecendo separadas. Ao sobrepor minha própria matriz da paz transracional com o conceito de Lederach, o resultado são as imagens abaixo, nas quais a conexão inextricável entre o interior e o exterior e os processos individual e coletivo na fronteira do contato humano em movimento torna-se aparente. Essa interpretação da pirâmide combina a noção de pazes transracionais à abordagem prática de Lederach. A Figura 5 apresenta o primeiro passo para apresentar uma vista do alto das camadas:

Figura 5: As camadas intrapessoais da pirâmide de Lederach; vista de cima

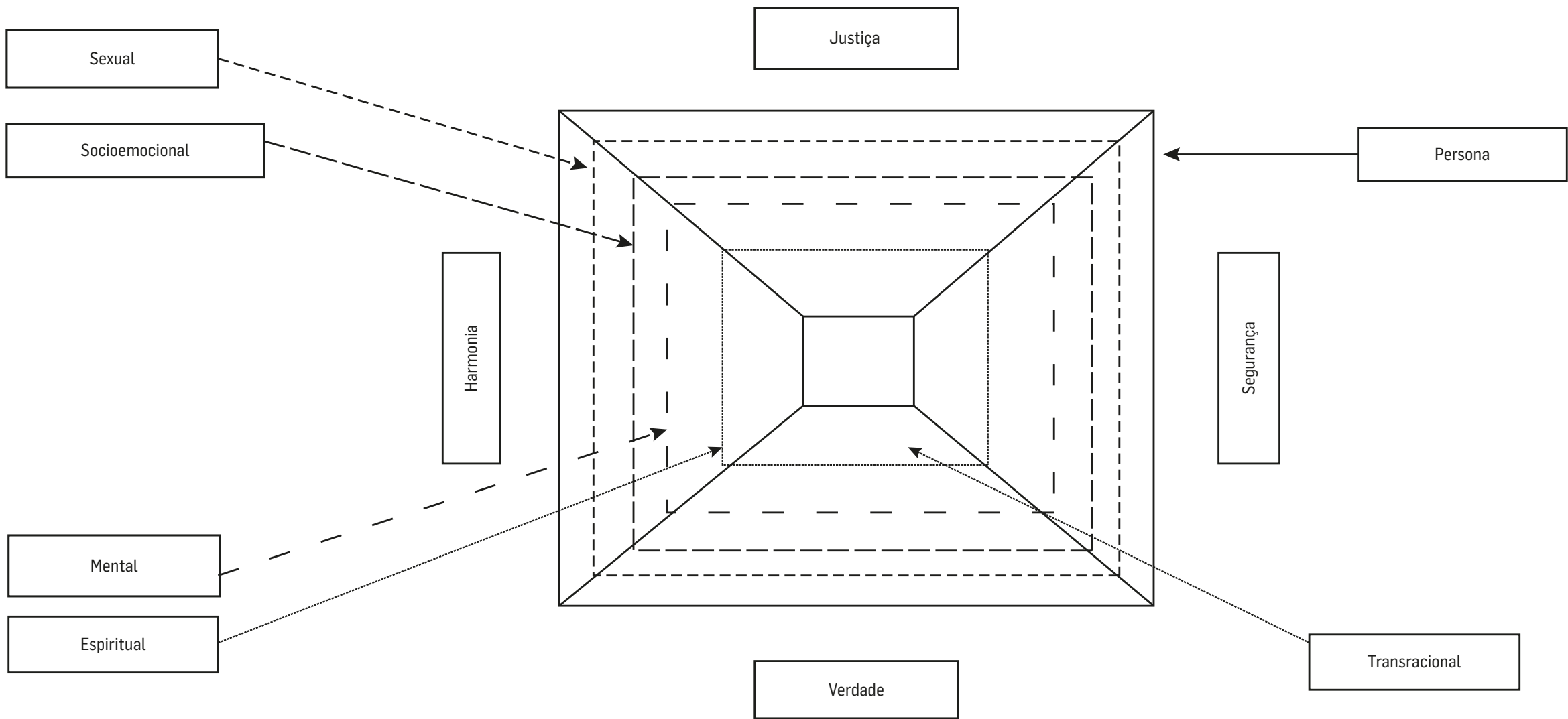

Fonte: Dietrich, 2011, p. 356. 
Praticamente todas as escolas da psicologia humanista descrevem as estratificações intrapessoais, que são, de maneira notável, similares às estratificações sociais. Esse também é o pressuposto básico do princípio tântrico da correspondência. Eu as sigo. As camadas localizadas fora da superfície pessoal e material da persona podem ser chamadas de camadas da família, comunidade, sociedade, policidade e globalidade. A não ser pelo termo policidade, todos os demais são amplamente aplicados na psicologia sistêmica e transpessoal (Ruppert, 2002) e entendidos no discurso do dia a dia. Policidade é uma palavra artificial. Nós a cunhamos para expressar a consciência humana primordial da nossa existência no tempo e espaço físico, que é a precondição para a compreensão mental de nós mesmos como seres sociais e de qualquer ideia acerca da organização social.

Todas essas camadas influenciam de modo silencioso os conflitos interpessoais à medida que surgem na superfície visual da persona. Ou seja, se eu tiver um conflito pessoal com alguém, minha família, parentesco, sociedade e policidade desempenham um papel invisível e silencioso, mas significativo. 0 mesmo pode ser dito para as camadas intrapessoais. Os aspectos sexuais, emocionais, mentais e espirituais de minha personalidade influenciam o comportamento na superfície e meu desempenho num conflito. Nenhum episódio pode ser entendido apenas como um conflito estritamente interpessoal ou intersocial, mas sempre transpessoal ou trans-societal - o distúrbio do equilíbrio relacional no interior de um único sistema. Como um segundo passo, portanto, adiciono ao diagrama acima aquelas camadas que estão localizadas fora da superfície, ou máscara, de uma persona. Nessa abordagem pragmática, considero o princípio tântrico da correspondência: o que se passa no interior é refletido no exterior. Com isso, chego ao diagrama final e completo da Paz Transracional, como mostra a Figura 6:

Figura 6: As camadas inter e intrapessoais da pirâmide de Lederach: o diagrama da Paz Transracional; vista de cima

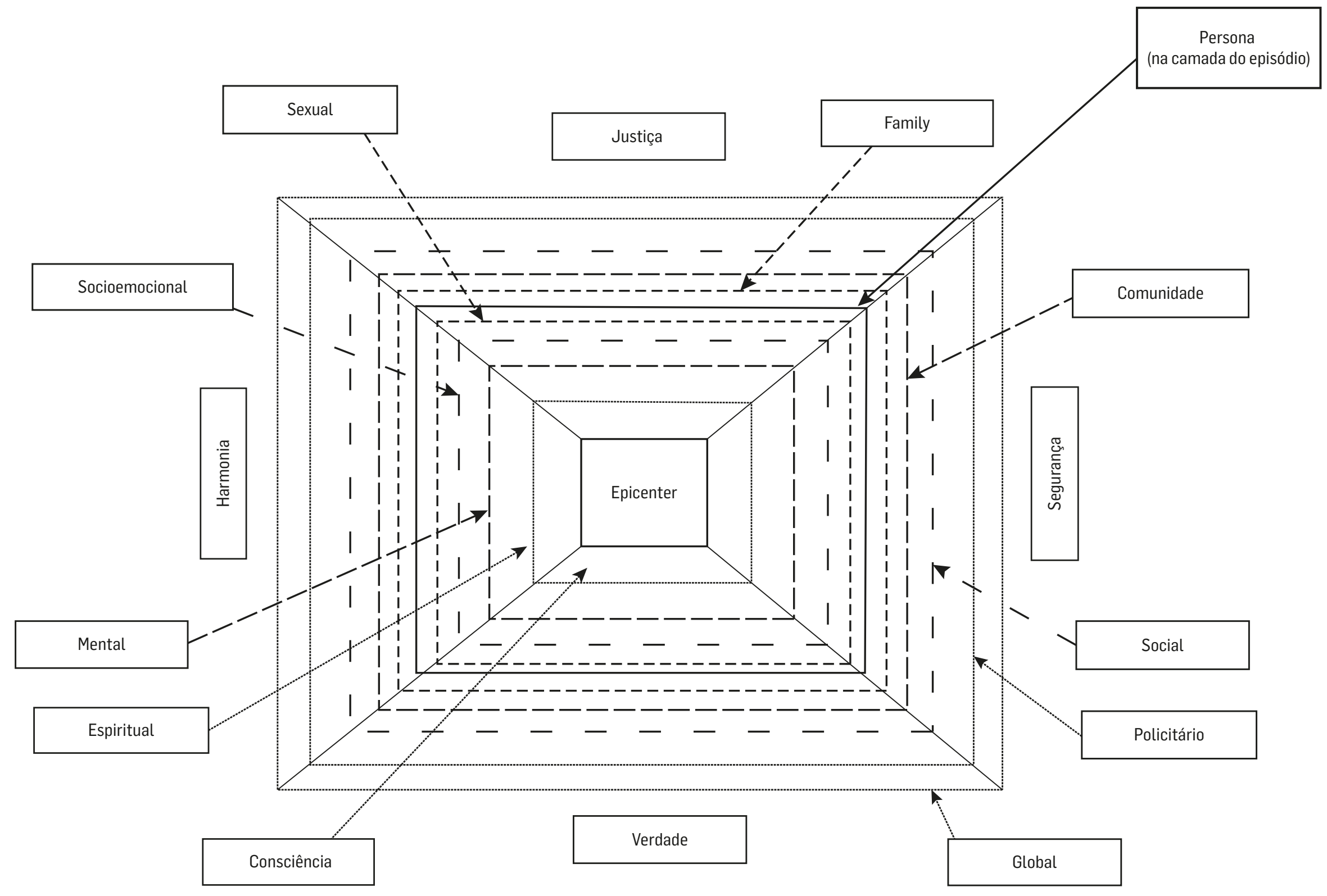

Fonte: Dietrich, 2011, p. 357. 
ANO 15 • NÚMERO 28 • 1은. 2018 • ORGANICOM

UMA BREVE INTRODUÇÃO À PESQUISA SOBRE PAZ TRANSRACIONAL

De suma importância para a compreensão desse diagrama é o princípio da homeostase sistêmica, que aqui aparece simplesmente como um aspecto de equilíbrio. A Figura 6 precisa ser vista como uma planta baixa metafórica da pirâmide de Lederach, concebida como que flutuando nas correntes da vida. Se um dos lados estiver sobrecarregado, a construção virá abaixo. Da mesma forma, se um único aspecto for enfatizado em demasia no trabalho de conflito, como, por exemplo, a segurança, então a harmonia será enfraquecida, e a verdade e a justiça serão desestabilizadas. Aplicável a todas as combinações, 0 sistema desmorona assim que um ponto da bifurcação é alcançado. Pela mesma razão, uma construção virá abaixo, um barco vai adernar, quando os pisos superiores se apoiarem demasiadamente nas fundações; entretanto, trabalhar apenas nas fundações significa que nunca haverá um teto. Aplicada ao trabalho de conflito, essa metáfora enfatiza a importância de serem consideradas todas as inter-relações individuais e sociais no sistema do conflito, assim como todos os níveis da pirâmide. Afinal, nem mesmo o ornamento mais delicado sobreviveria se as paredes fossem instáveis ou se não estivessem assentadas numa fundação sólida. Assim, todas as camadas categorizadas anteriormente são relevantes. Enquanto trabalhamos numa, não deveríamos perder de vista as outras, pois o desequilíbrio entre elas pode fazer desabar o sistema inteiro. Para dar um exemplo extremo, poderíamos pensar em alguém trabalhando exclusivamente na camada espiritual e negligenciando as camadas sociais e intelectuais.

É possível fazer objeções e sugerir que o modelo da pirâmide, com seus níveis verticais, temas horizontais, camadas intrapessoais e interpessoais, todos conectados pelo desejo de harmonia, seja demasiado complexo para ter alguma aplicação prática. Essa objeção até pode ser justificada, em especial com relação à minha ênfase de que, quando consideradas num contexto relacional e situacional, elas não são categorias claramente distintas, mas apenas ferramentas comuns e sobrepostas para uma compreensão significativa. Entretanto, considerando-se que os sistemas sociais são inevitavelmente dinâmicos e, gostemos ou não, complexos, essa racionalidade tem um alcance extremamente limitado. Como consequência, o trabalho de conflito que toma como foco o epicentro do contexto em vez da superfície do episódio não deve se limitar a uma racionalidade reducionista. A complexidade das inter-relações sociais só pode ser descrita em termos transracionais. Por conseguinte, a pesquisa sobre paz transracional não pode limitar o uso de suas metodologias aplicadas à engenharia racional de conflitos. São necessários métodos que contemplem todos os aspectos da natureza humana porque todos esses definem os conflitos e a maneira de lidar com eles. Os trabalhadores de conflitos necessitam de um conjunto de ferramentas que lhes permita aplicar a racionalidade, e também de métodos que operem nas camadas sexuais, emocionais, mentais e espirituais correspondentes às camadas da família, comunidade, sociedade e policidade. Esses métodos devem ser eficazes nas camadas subconscientes, conscientes e superconscientes. Encontramos essa caixa de ferramentas ideal na abordagem de John Paul Lederach à transformação elicitiva de conflito, que opera principalmente com as realidades presentes e suas inter-relações sistêmicas complexas. 0 recurso mais importante para o trabalho de paz sustentável é a teia relacional das pessoas envolvidas.

\section{O QUE É TRANSFORMAÇÃO ELICITIVA DE CONFLITO?}

0 adjetivo "elicitive" não aparece em nenhum dicionário padrão da língua inglesa. Lederach (1995) deriva a palavra do verbo "to elicit", com o significado de induzir ou evocar. 0 termo foi usado em primeiro lugar na terapia Gestalt e na psicologia humanista como um sinônimo para "evocativo". Refere-se a processos nos quais os terapeutas oferecem uma moldura conceitual, mas não uma diretriz para a transformação do cliente (O'Connor; Seymour, 1992). Isso diz muito sobre seu uso nos estudos de paz e no trabalho de conflito aplicado. "Elicitivo" sugere, nesse contexto, que a energia relacional dos grupos em conflito oferece o método e a direção da transformação. A transformação elicitiva de conflito, portanto, traz à tona, realça e catalisa o conhecimento existente ou comunitariamente construído com relação à transformação de conflito entre indivíduos, grupos e comunidades, enquanto as abordagens prescritivas preferem modelos pré-fabricados. A definição de Lederach não propõe simplesmente um novo rótulo para técnicas antigas e objetivas. 0 termo refere-se de maneira fundamental à 
mudança transracional no entendimento de paz e conflito (Dietrich, 2008, 2011). Mais precisamente, a transformação elicitiva de conflito é a consequência metodológica da filosofia da paz transracional.

Da abordagem metodológica origina-se uma compreensão do conflito, do trabalho de conflito e do perfil pessoal exigido para um trabalhador de conflito que difere, de forma significativa, das visões convencionais do trabalho de conflito e da transformação de conflito prescritiva que pode ser observada, por exemplo, nos manuais das missões da Organização das Nações Unidas (ONU). Não se trata aqui de disponibilizar manuais, remédios ou soluções pré-fabricadas; trata-se de acreditar na energia transformadora que brota das partes em conflito e de suas relações. E, de acordo com o princípio da ressonância, pressupõe que o trabalhador de conflito perceba essa energia e ofereça uma moldura adequada para a transformação sem assumir a liderança ou impor seus conceitos aos grupos em conflito.

A transformação elicitiva de conflito é um método, uma arte e uma ciência. Darei uma lista de algumas ferramentas práticas. Mas antes de fazê-lo, desejo falar sobre o treinamento de trabalhadores de conflito elicitivos, uma vez que esse método exige habilidades pessoais diferentes e mais sutis do que a abordagem prescritiva. Essa questão deve ser considerada nos programas de treinamento. Lederach (1997), já nos anos 90 do século passado, reivindicava um treinamento em construção de capacidades e relacionamento estratégico. Com base nisso, desenvolvemos na Universidade de Innsbruck, na Áustria, um programa de treinamento acadêmico que enfatiza, dentre outros aspectos, as habilidades de contato pessoal dos futuros trabalhadores de conflito. Extraímos dos princípios gerais da psicologia humanísta alguns postulados e os ancoramos em nosso currículo. Portanto, o ABC dos pré-requisitos dos trabalhadores de paz elicitivos que promovemos na nossa abordagem consiste em:

- consciência (A-wareness) dos próprios limites físicos, emocionais, mentais e espirituais;

- equilíbrio (B-alance) entre a compaixão e autoproteção; e

- comunicação (C-ommunication) congruente.

Daí decorre que colocamos a personalidade do trabalhador de conflito no foco da atenção em nosso treinamento acadêmico. Consideramos o trabalhador de paz em atividade como um fator de equilíbrio, contudo nada mais do que apenas outro elemento, um "terceiro" (Ury, 2000) no conflito, que aqui é entendido relacionalmente como um sistema social disfuncional. Acredita-se que o trabalhador de paz jamais deverá ser neutro ou não-partidário, mas que, no melhor dos casos, dever ser partidário de todos. É requerida alta consciência do Self, da realidade circundante de dado cenário e dos conceitos de sua própria mente para que não se perca em fantasias, preconceitos e valores, mas seja capaz de ecoar as afirmações, comportamentos, sentimentos, carências e exigências das partes.

As raízes da transformação elicitiva de conflitos na psicologia humanísta podem ser facilmente identificadas nesses postulados. Permitam-me recordar as características dos autorrealizadores que Abraham Maslow (1970), um dos fundadores da psicologia humanísta, apresentou no final dos anos 60 do século XX. Não entrarei no debate metodológico acerca de sua obra, porque em Innsbruck não estamos interessados na discussão sobre quem foi historicamente ou está nesta época autorrealizado, mas usamos a lista de Maslow como se fosse um tipo de orientação, bem conscientes de que poucos alcançam isso. Aceitamos que, embora todos teoricamente sejamos capazes de autorrealização, a maioria de nós não o fará ou, se sim, apenas num grau limitado. Além disso, Maslow (1970) afirmou que não há seres humanos perfeitos, ou seja, não equipara autorrealização com perfeição. A autorrealização envolve unicamente atingir o próprio potencial. Portanto, não alegamos criar pessoas que sejam percebidas como homens ou mulheres superiores, da categoria de Gandhi, Albert Schweitzer, Martin Luther King, Nelson Mandela ou Madre Teresa, mas oferecemos uma moldura conceitual possibilitando que nossos alunos testem seu 
potencial e vislumbrem caminhos para suas autorrealizações. As pessoas alcançam a autorrealização sempre da sua própria exclusiva maneira, mas há uma tendência de que compartilhem certas características. Maslow identifica 15 características dos autorrealizadores. Eu as amplio com um aspecto intercultural e as enumero aqui, um pouco modificadas, como as 20 virtudes centrais dos trabalhadores de paz elicitivos de acordo com nossa experiência da última década.

Trabalhadores de conflito elicitivos:

1. percebem a realidade eficientemente e têm tolerância à incerteza e ao estresse;

2. aceitam a si mesmos, aos outros e à natureza humana da maneira que se apresentam;

3. são espontâneos, naturais e genuínos em ação e pensamento;

4. são centrados no problema e não precisam de muitos elogios e popularidade;

5. são capazes de concentrar-se intensamente e têm senso de humor construtivo;

6. são benevolentes, solidários, pacientes e preocupados com o bem-estar dos outros;

7. fazem as coisas de maneira criativa, mesmo quando não têm muito talento para elas;

8. são capazes de adotar ou abandonar as convenções, embora não sejam propositalmente não convencionais;

9. são independentes, autossuficientes e autônomos;

10. apreciam experiências simples e corriqueiras;

11. estabelecem relacionamentos, amizades e amor interpessoais satisfatórios com algumas pessoas;

12. sentem uma certa necessidade por privacidade e solitude;

13. são democráticos e não preconceituosos;

14. mantêm padrões éticos sólidos, embora não necessariamente num sentido convencional;

15. são capazes de se desapegar da sua própria cultura;

16. conseguem adotar ou abandonar convenções culturais;

17. são capazes de comparar culturas sem julgamento ou atribuição de culpa;

18. aperfeiçoam suas energias e qualidades constantemente;

19. tratam os conflitos como construções da mente e não como fatos objetivos que poderiam ser consertados com os remédios apropriados; sabem que os conflitos (somente) podem ser desconstruídos na mente das partes (seres humanos); 
20. conhecem as "experiências culminantes": os sentimentos de êxtase, deslumbramento e contemplação, a perda de localização no tempo e no espaço.

Embora a maioria dessas características sejam simultaneamente sabedoria popular e cientificamente testadas, o último ponto poderia surpreender, porque parece indicar mais uma direção espiritual ou religiosa individual do que um trabalho de paz aplicado a comunidades e sociedades. Trata-se, entretanto, de uma decorrência necessária do sistema de camadas transracionais que discuti anteriormente. Tendo em vista que a consciência espiritual-policitária origina-se da experiência, os seres humanos entram neste mundo de tempo e espaço como folhas numa árvore (Naranjo, 2005). Isso faz a diferença no sentir, pensar, falar e agir para as abordagens morais, modernas e pós-modernas. Isso acalma os medos arcaicos pela vida ou pela sobrevivência e une as pessoas com a existência. Portanto, a procura pela experiência de paz na transformação elicitiva de conflito iguala-se à busca espiritual pela experiência culminante no misticismo.

É possível afirmar que a transformação elicitiva de conflito tem muito a ver com coragem: atrever-se a novas tarefas e métodos e arriscar-se a fracassar; não ter medo de expressar os pensamentos e sentimentos e arriscar-se a se tornar impopular; combinar elementos narrativos de maneira não convencional ou inesperada e com bom humor; e aceitar a intuição como um aspecto legítimo da própria personalidade, que não necessariamente apresenta o mesmo padrão comunicativo da razão. Os trabalhadores de conflito elicitivos compartilham a determinação de encontrar ordem em situações caóticas, o interesse em descobrir problemas incomuns assim como meios e maneiras de transformação, a habilidade de fazer novas conexões e desafiar pressupostos tradicionais, a habilidade de equilibrar criação de ideias com julgamento e teste, o desejo de estender as fronteiras de sua competência e, além disso, também são mais motivados pela tarefa em si do que pelas recompensas externas como dinheiro, avaliações ou reconhecimento.

Esses são tanto o objeto como o método de nosso treinamento em transformação elicitiva de conflito, e tentamos inspirar em nossos alunos a confiança de que serão capazes de aplicá-los quando se tornarem praticantes no campo do trabalho de conflito. Porém, mesmo que o lúdico e a intuição sejam um bom começo para o trabalho de conflito, também é bom estar equipado com uma caixa de ferramentas de métodos testados e estar estruturado desde o início para ser flexível quando as inevitáveis surpresas do trabalho de conflito surgirem.

\section{MÉTODOS, FERRAMENTAS E PRINCÍPIOS}

O conjunto de ferramentas dos métodos aplicáveis na transformação elicitiva de conflito abrange praticamente todas as técnicas conhecidas orientadas para a respiração, a voz e o movimento que têm sido desenvolvidas no âmbito da psicologia humanísta, yoga, artes marciais, dança, meditações dinâmicas, psicodrama, teatro expressivo e outras mais. Norbert Koppensteiner apresenta alguns deles de modo mais extenso. Outros podem ser encontrados em Dietrich, 2011 (em alemão) e 2013 (mesma publicação traduzida para o inglês). Portanto, enumero aqui sem maiores explicações apenas alguns exemplos, como respiração holotrópica, clarity process, vipassana, monólogo e diálogo intuitivos, paralinguística, mantra, escuta ativa, comunicação não-violenta, interação centrada no tema, five rhythm dance, butô, capoeira, aikido, teatro do oprimido, teatro para a vida, para ficar apenas com alguns.

Oferecemos treinamento básico nesses métodos para os nossos alunos em Innsbruck, mas cada uma dessas técnicas exige muito tempo e prática antes que alguém possa ser considerado um mestre. E ninguém pode ser mestre em todas. Entretanto, conhecer e experimentar algumas delas é decisivo no trabalho de conflito elicitivo. A aplicação de uma específica técnica num conflito deve ser avaliada no local, e a responsabilidade é assumida pelo trabalhador de conflito, que recorrerá à sua própria experiência para decidir se a técnica concreta escolhida é a ferramenta adequada. Porém, temos observado que 
ANO 15 • NÚMERO 28 • 1ํ SEM. 2018 • ORGANICOM

UMA BREVE INTRODUÇÃO À PESQUISA SOBRE PAZ TRANSRACIONAL

o conhecimento das técnicas aumenta imensamente a fantasia metodológica do trabalhador de conflito. Elas os tornam exploradores, cientistas e artistas do trabalho de conflito. Ou seja, mediante o conhecimento e a vivência de muitas dessas técnicas, os trabalhadores de conflito ficam inclinados a explorar e experimentar com novos métodos contextuais derivados da situação e da relação com as partes em conflito. É exatamente o que indica o princípio elicitivo da ressonância. Essa habilidade e coragem caracterizam trabalhadores de conflito qualificados. E os tornam capazes de oferecer uma moldura conceitual adequada para as partes em conflito de modo a explorar novas opções e alternativas para a sua interação-transformação. Pois se considera que só é possível falar sobre transformação de conflito bem sucedida quando os grupos elaboram por si mesmos e, por fim, concebem pelo menos três opções (novas) para sua interação, sentindo-se livres para escolhê-las ou rejeitá-las sem temer punição ou desejar recompensa (Satir, 1991).

Na medida em que defendemos o princípio da Interação Centrada no Tema (Cohn, 2004), segundo o qual é necessário ser estruturado para que seja flexível na transformação de conflito, desenvolvemos um método específico que chamamos de mapeamento elicitivo de conflito. Esse é o assunto principal do volume três da minha trilogia Muitas Pazes, sobre pazes transracionais e transformação elicitiva de conflito. Josefina Echavarría Álvarez apresenta essa ferramenta, brevemente, neste volume. 0 mapeamento elicitivo de conflito não é igual ao mapeamento do conflito convencional. É uma ferramenta para achar e conservar a orientação no trabalho de conflito aplicado. Consiste numa ajuda ao trabalhador de conflito na análise das relações disfuncionais para encontrar equilíbrio na confusa teia de temas, níveis e camadas da pirâmide do conflito. Metodologicamente, origina-se mais do mapeamento mental do que do tradicional mapeamento da crise ou do conflito. Nosso método fundamenta-se nos três princípios: correspondência, ressonância e homeostase.

A correspondência é um princípio tântrico segundo o qual tudo o que acontece entre os indivíduos tem seu equivalente nas pessoas. Assim, a narrativa sobre um conflito interpessoal revela muito ao trabalhador de paz elicitivo acerca dos processos, energias e bloqueios internos das partes envolvidas. Deve-se considerar que toda alteração das questões e relações externas exerce um impacto na condição interna das pessoas envolvidas e vice-versa. A energia de qualquer conflito, como uma questão estritamente relacional, sempre vai encontrar seu fluxo ao longo dessas linhas. 0 trabalho de conflito, portanto, pode ser iniciado com as camadas pessoais como com as relacionais. 0 trabalhador de conflito tem apenas que manter o princípio da correspondência em mente e aplicá-lo ao prover a moldura estrutural para o esforço de transformação e, eventualmente, ao oferecer estímulos.

A ressonância também é um princípio tântrico que se aplica em primeiro lugar nas relações dos grupos conflitantes. Ou seja, num conflito nós veremos e ouviremos uma narrativa expressa sobre as controvérsias na superfície, mas as partes simultaneamente ressoam umas com as outras em todas as camadas às quais me referi no primeiro capítulo deste ensaio. Uma vez que essas camadas estão interconectadas e influenciam umas às outras, descobriremos que a força motriz de um conflito raramente é o assunto do episódio na superfície, mas um bloqueio ou irritação em uma das camadas mais profundas. A energia da vida deriva-se do epicentro e se irradia por todas as camadas da existência até tornar-se visível na superfície do episódio. Essa irradiação é influenciada por todos os aspectos dos encontros e relações humanas. Se for bloqueada ou irritada, nós a percebemos como um conflito. Por conseguinte, a transformação elicitiva de conflito tenta descobrir os aspectos conflitantes o mais próximo possível do epicentro. Já que o transformador de conflito também é um ser humano, ressoará da mesma maneira com as partes. Assim, são muito importantes a autoconsciência e a consciência do que existe em torno, assim como dos próprios conceitos presentes naquele momento. É por isso que habilidades sutis de interação são fundamentais para os trabalhadores de conflito, pois é inevitável que se tornem um novo elemento do sistema social disfuncional e o alterem com sua mera presença. É preciso, portanto, que tenham consciência do efeito de sua presença, como se relacionam com as partes envolvidas e mudam seu ambiente e relações. Um trabalhador de conflito elicitivo bem treinado contribuirá para o equilíbrio do sistema, enquanto atores sem consciência podem danificar e destruir ainda mais. 
Por fim, homeostase é um termo técnico que adotamos da Teoria Geral de Sistemas (Bertalanffy, 1968), que descreve a propriedade de um sistema que regula seu ambiente interno e tende a conservar uma estabilidade dinâmica. Os conflitos resultam do distúrbio da homeostase nos sistemas sociais. A transformação elicitiva de conflito, por isso, contribui para uma mudança gradual do desequilíbrio homeostático em um sistema social por meio da busca do restabelecimento do equilíbrio em todas as camadas, níveis, e entre todos os temas, com plena consciência de que, devido ao caráter dinâmico dos sistemas sociais, o equilíbrio não é um status final alcançável, mas tão somente um farol que orienta na ação.

Esses três princípios, baseados na filosofia transracional, são as principais ferramentas para o mapeamento elicitivo de conflito. São úteis para traçar um mapa do conflito, compreender sua "paisagem". De certo modo, equivalem a bússola, sonar e mapa para o trabalhador de conflito, ajudando-o a fazer uma imagem do conflito. É útil porque dá orientação. Mas ainda é preciso enfatizar que o mapa turístico não é a paisagem; o mapa do conflito não é o conflito, é uma ferramenta útil. Ainda é preciso toda arte e ciência para que o trabalhador de conflito se movimente e atue no conflito social real. Por essa razão, consideramos fundamental o treinamento de todas as virtudes mencionadas acima antes que o trabalhador de conflito possa se envolver nos problemas dos outros.

\section{CONCLUSÃO}

A transformação elicitiva de conflito é um princípio operacional que se ancora nos insights da filosofia da paz transracional e oferece o mapeamento elicitivo de conflito como ferramenta para o trabalho de conflito aplicado. Os seguintes princípios são os ingredientes fundamentais para esse tipo de trabalho de conflito: 1) correspondência das camadas intrapessoais e interpessoais; 2) homeostase entre os temas gerais de dado conflito; e 3) ressonância entre as partes, assim como entre 0 trabalhador de conflito e cada um dos participantes em todas as camadas. É aplicável em todos os níveis da sociedade - líderes de cima, nível médio e base popular, pois todos são atores humanos envolvidos pelo sistema mundial global. Em consequência, esse método reconhece a importância das necessidades materiais básicas para a vida humana e, portanto, para as relações humanas, porém pressupõe que os conflitos são raramente desencadeados apenas por uma falta de equilíbrio na distribuição de recursos ou por um simples choque de interesses materiais, seja num contexto individual, comunitário, societal ou global. Baseia-se, muito mais do que isso, na crença de que os conflitos são criados nas mentes dos seres humanos. Portanto, todos os aspectos da natureza humana, não apenas os materiais, devem ser considerados no trabalho de conflito aplicado, uma vez que os conflitos somente podem ser transformados nas mentes dos seres humanos, como tão bem declara a Unesco (1945) no preâmbulo de sua constituição.

Tradução de Neuza L. R. Vollet.

\section{REFERÊNCIAS}

BERTALANFFY, Ludwig von. General system theory: foundations, development, applications. New York: Georg Braziler, 1968.

BHARATI, Swami Veda. Yoga-sūtras of Patañjali: with the exposition of Vyāsa. Honesdale: The Himalaya Institute, 1986. (Samādhi-pāda, 1).

COHN, Ruth. Von der Psychoanalyse zur themenzentrierten Interaktion: von der Behandlung einzelner zu einer Pädagogik für alle. Stuttgart: Klett-Cotta, 2004. 
DIETRICH, Wolfgang. Variationen über die vielen Frieden: Band 1: Deutungen. Wiesbaden: Springer VS, 2008. [Tradução em inglês: Interpretations of peace in History and culture. London: Palgrave Macmillan, 2012. (Many Peaces, 1).

Variationen über die vielen Frieden: Band 2: Elicitive Konflikttransformation und die transrationale Wende in der Friedenspolitik. Wiesbaden: Springer VS, 2011. [Tradução em inglês: Elicitive conflict transformation and the transrational turn in peace politics. London: Palgrave Macmillan, 2013. (Many Peaces, 2).]

GALTUNG, Johan. Cultural violence. Journal of Peace Research, London, v. 27, n. 3, p. 291-305, 1990.

LEDERACH, John Paul. Preparing for peace: conflict transformation across cultures. Syracuse: Syracuse University Press, 1995.

LEDERACH, John Paul. Building peace: sustainable reconciliation in divided societies. Washington: United States of Peace Press, 1997.

LEDERACH, John Paul. The little book of conflict transformation: clear articulation of the guiding principles by a pioneer in the field. Intercourse: Good Books, 2003. [Tradução em português: Transformação de conflitos. São Paulo: Palas Athena, 2012.]

MASLOW, Abraham. Motivation and personality. New York: Harper \& Row, 1970.

NARANJO, Claudio. The one quest. a map of the ways of transformation. Nevada City: Gateways Books, 2005.

O'CONNOR, Joseph; SEYMOUR, John. Neurolinguistisches Programmieren: Gelungene Kommunikation und persönliche Entfaltung. Freiburg: VAK Verlag, 1992. [Tradução em inglês: Introducing neuro-linguistic programming: psychological skills for understanding and influencing people. London: Mandala, 1990.]

QUITMANN, Helmut. Humanistische Psychologie. Göttingen; Bern; Toronto; Seattle: Hogrefe, 1996.

RUPPERT, Franz. Verwirrte Seelen: Der verborgene Sinn von Psychosen: Grundzüge einer systemischen Psychotraumatologie. Munich: Kösel, 2002.

SATIR, Virginia et al. The Satir model: family therapy and beyond. Palo Alto: Science and Behaviour Books, 1991.

UNESCO - UNITED NATIONS EDUCATIONAL, SCIENTIFIC AND CULTURAL ORGANIZATION. The UNESCO Constitution. London: Unesco, 1945. Disponível em: <https://bit.ly/leGNuND>. Acesso em: 15 maio 2013.

URY, William. The third side: why we fight and how we can stop. New York: Penguin, 2000.

WILBER, Ken. Sex, ecology, spirituality. the spirit of evolution. Boston: Shambala Publications, 1995.

Texto recebido em 10.05.2018 e aprovado em 20.06.2018. 
ANO 15 • NÚMERO 28 • 1으N. 2018 • ORGANICOM

UMA BREVE INTRODUÇÃO À PESQUISA SOBRE PAZ TRANSRACIONAL 